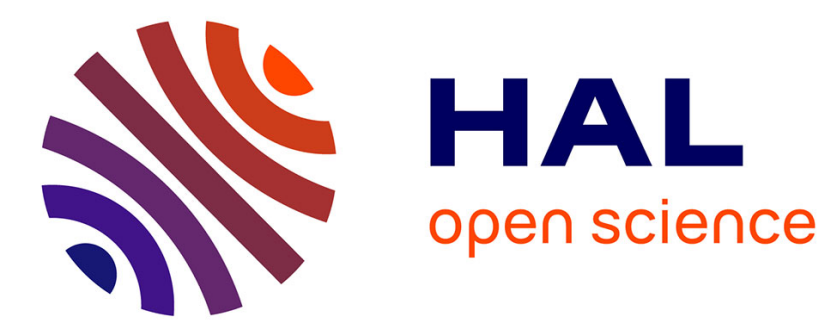

\title{
Physical and Mechanical Characterization of Soya, Colza and Rye Seeds
}

Cédric Degouet, Blaise Nsom, Eric Lolive, André Grohens

\section{To cite this version:}

Cédric Degouet, Blaise Nsom, Eric Lolive, André Grohens. Physical and Mechanical Characterization of Soya, Colza and Rye Seeds. Applied Rheology, 2007, 17 (3), pp.36546-1 - 36546-7. hal-00527394

\section{HAL Id: hal-00527394 \\ https://hal.univ-brest.fr/hal-00527394}

Submitted on 20 Oct 2010

HAL is a multi-disciplinary open access archive for the deposit and dissemination of scientific research documents, whether they are published or not. The documents may come from teaching and research institutions in France or abroad, or from public or private research centers.
L'archive ouverte pluridisciplinaire HAL, est destinée au dépôt et à la diffusion de documents scientifiques de niveau recherche, publiés ou non, émanant des établissements d'enseignement et de recherche français ou étrangers, des laboratoires publics ou privés. 


\title{
Physical and Mechanical characterization of soya, colza and rye seeds
}

\author{
Cédric Degouet, Blaise Nsom, Eric Lolive and André Grohens
}

Université de Bretagne Occidentale. Laboratoire d'Ingénierie Mécanique et Electrique (LIME/PMB). IUT de Brest. BP 93169. Rue de Kergoat. 29231. BREST Cedex 3 - France.

\begin{abstract}
This paper presents characterization of the following dry granular materials - soya, colza and rye seeds - was carried out. The physical properties of the grain and the materials are useful for characterizing the materials' behavior during flow, while the external conditions, in particular, consolidation, determine storage and handling conditions. The specific densities of the grains and of the materials as a whole (compacity or porosity, and critical angles) were measured. The flow functions were determined by modified shear box testing. Then, the internal friction angles and the flowability index for each granular material were obtained. Indeed, the behavior of a flowing granular material results from these two groups of factors and is characterized by the flowability, which is the ratio of highest consolidation stress and unconfined yield strength. In practice, the flowability index is used to classify materials, so that the larger the flowability index, the smaller the bulk solids strength will be in relation to the consolidation stress, and therefore the higher the flowability of the bulk solid.
\end{abstract}

\section{Keywords}

Characterization, Colza seeds, Dry grains, Flow function, Flowability, Granular material, Modified shear box testing, Rye seeds, Silos, Soya seeds.

\section{1 - Introduction}

In the food-processing industry, cereals occupy a central position as they constitute the basis of man's staple diet. They are made of macroscopic grains and are usually stored, handled, transported and manufactured in this form. The bulk flow of these products occurs in many unitary operations: drying, storage, extrusion, granulation, grinding, fluidization, packing, etc , soit is important for an engineer to be able to predict the behavior of the granular material used.

To characterize a continuous medium, rheologists write the stress-strain equations for solids (e.g. elastic, plastic, elastoplastic behaviour), and stress-rate of strain equations for liquids (e.g. viscous, viscoelastic, viscoplastic behavior). Granular materials combine both the properties of divided solids and those of flowable liquids This behavior is due to the nature of the contact between the grains: on a small scale, since each grain is considered as an elastic solid, the unilateral characteristic of the contact and Coulomb's friction law are governed by the following relations:

$$
\begin{gathered}
d \cdot N=0 \quad ; \quad d \text { and } N \geq 0 \\
|\vec{T}| \leq f \cdot N
\end{gathered}
$$

where $N$ and $\vec{T}$ denote the normal and the tangential components of the contact force, respectively, $d$ is the interstice and $f$ the friction coefficient. These two inequalities introduce on a large scale (matters together) a yield below which the material will have a solid type behavior, while a flow will be possible if the yield is reached. 
Since 1950, many papers have been devoted to powder and grain flow using soil mechanics tests, which are based on Coulomb's laws of friction (Costet and Sanglerat, 1975). There are three main methods for characterizing the flowability of a granular material (Teunou, 1997). Unfortunately, each of them gives only a few specific properties of the medium and therefore none of them is satisfactory. Carr (1965a; 1965b; 1965c) determined the flow index and the fluidity index from a combination of powder characteristics which are easy to measure. This method allows a comparison of the flowability of different powder media but cannot characterize the intrinseque flowability of a given powder. In addition, it only considers stresses lower than those which exist inside industrial silos. The compression test (Peleg, 1977) characterizes the flowability by measuring the compressibility of a granular material, i.e. the decrease in porosity in relation to the compression stress. Testing food grains, Peleg (1977) showed that a correlation exists between compressibility and Jenike's flow index (1964), but Peleg's test cannot be used to design silos. Shear box testing characterizes the limit stress of failure after shearing using a known normal stress and following an imposed plane of failure. Jenike's method is based on the same principle as shear box testing, but in this test the consolidation of the material is applied within the cylindrical cell by applying twists, while for shear box testing, samples are previously consolidated in a separate bench. There are other methods based on the indirect determination of the flow functions, such as the triaxial test (Lancelot et al., 1994) and the biaxial test (Nowak and Schwedes, 1992), and others based on the direct determination of the flow functions (Williams et al., 1971; Haaker and Rademacher, 1983), but the Jenike equipment can be considered as the standard measuring device for the bulk solids technique.

Meanwhile, the flow properties can be analyzed by different methods (Svarovski, 1987; Schulze, 1996a; 1996b), the most common and rational being the Jenike test. Jenike, (1964) considering a granular material as an elasto-plastic continuous medium, gives a methodology to evaluate the grain flowability. Flowability is the capacity for a granular medium to acquire a desired specific behavior for a given application in a given environment (Prescott and Barnum, 2000).

This work covered soya, colza and rye seeds. The flowability of each of these granular solids was studied using modified shear box testing, capable of investigating the limit stress at the point of failure by shearing of a sample with its natural consolidation under a known normal stress and following an imposed plane of failure. The grains were characterized and their flowability was determined. In addition, the specific bulk characteristics and properties of a granular material that affect flow and that can in principle be measured are known as flow properties (Carr, 1965a; 1965b; 1965c). Such physical grain properties measured in this work include densities, porosity and critical angles. Because of the size of the grains, the absence of very fine particles or humidity, the Van der Waals, electrostatic and surface tension forces were ignored.

\section{2 - Description of the tested granular materials}

Every year, the "Brest Chamber of Commerce" in France, which manages the silos at the "Brest Commercial Port", handles millions of kilograms of soya, colza and rye seeds. Samples of these granular solids were used to characterize their flowability in application to silo discharge operations (GDR Midi, 2004). Soya seeds are light yellow hard beads with a $\mathrm{d}_{50}$ equal to $6.1 \times 10^{-3} \mathrm{~m}$, while Colza seeds are black hard beads with a $\mathrm{d}_{50}$ equal to $2.3 \times 10^{-3} \mathrm{~m}$, and rye seeds have a rounded cylindrical shape, and are brown-green in color with a $\mathrm{d}_{50}$ equal to $3.5 \times 10^{-3} \mathrm{~m}$. The granulometry of each of these materials was characterized using appropriate sieves. Results are given in fig.1 (a)-(c). 


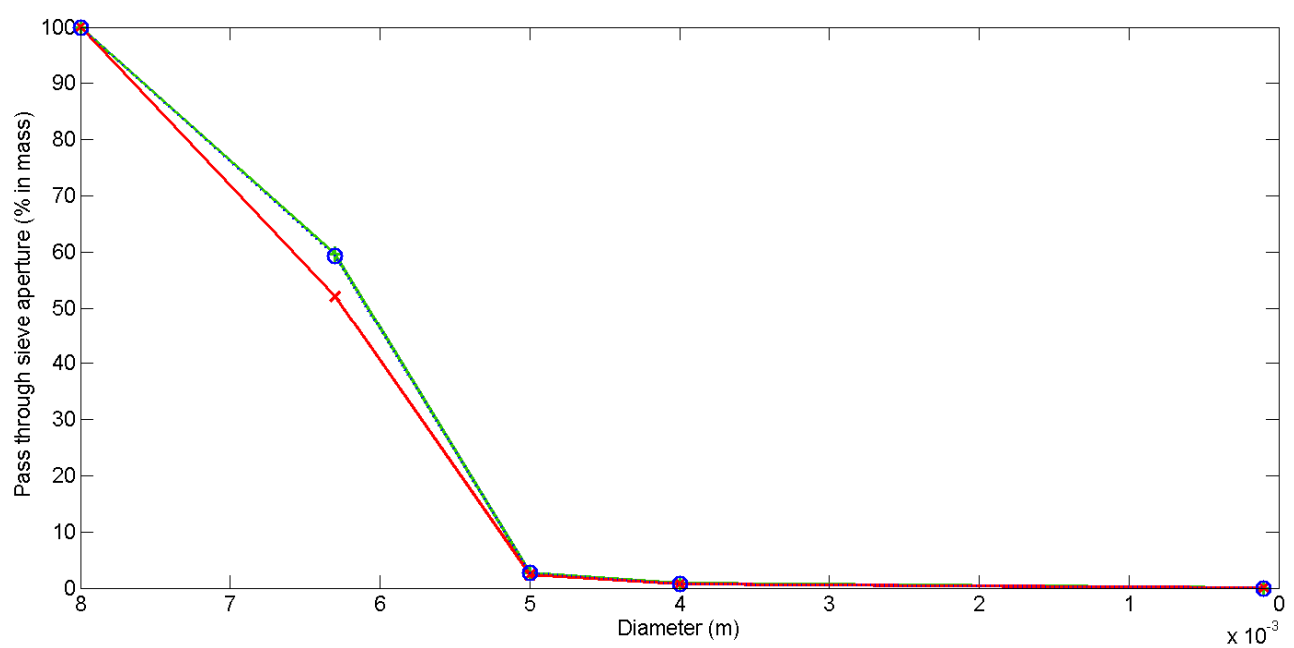

(a)

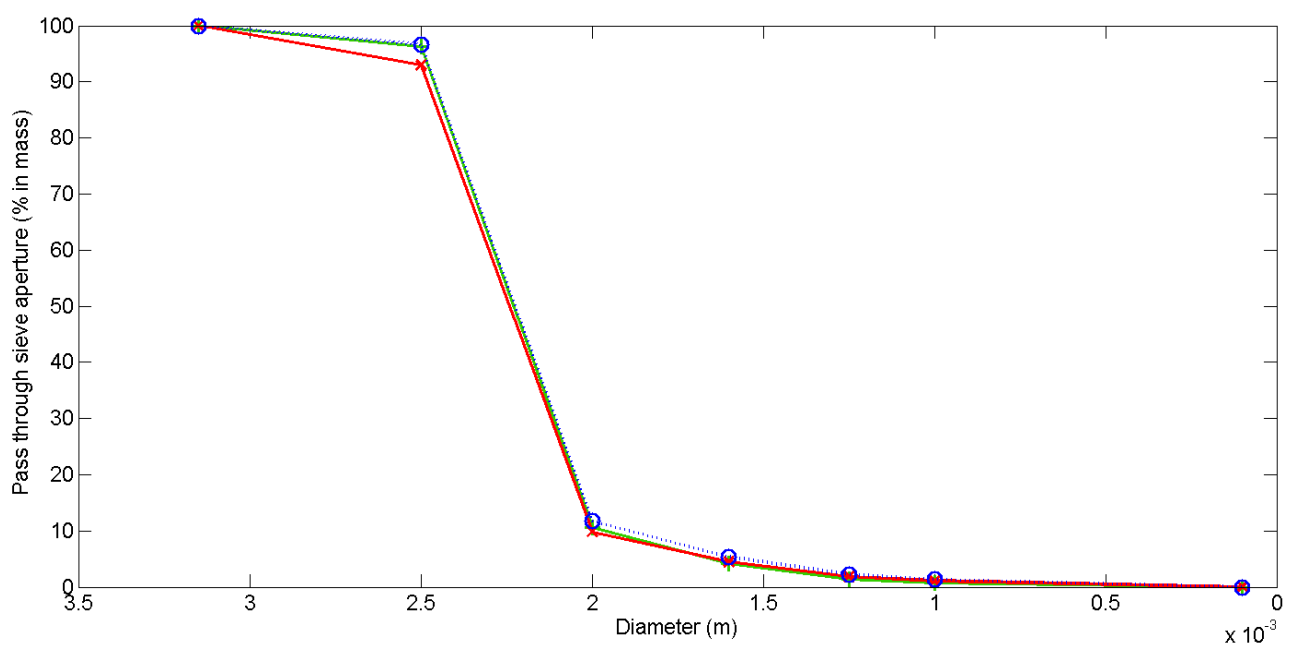

(b)

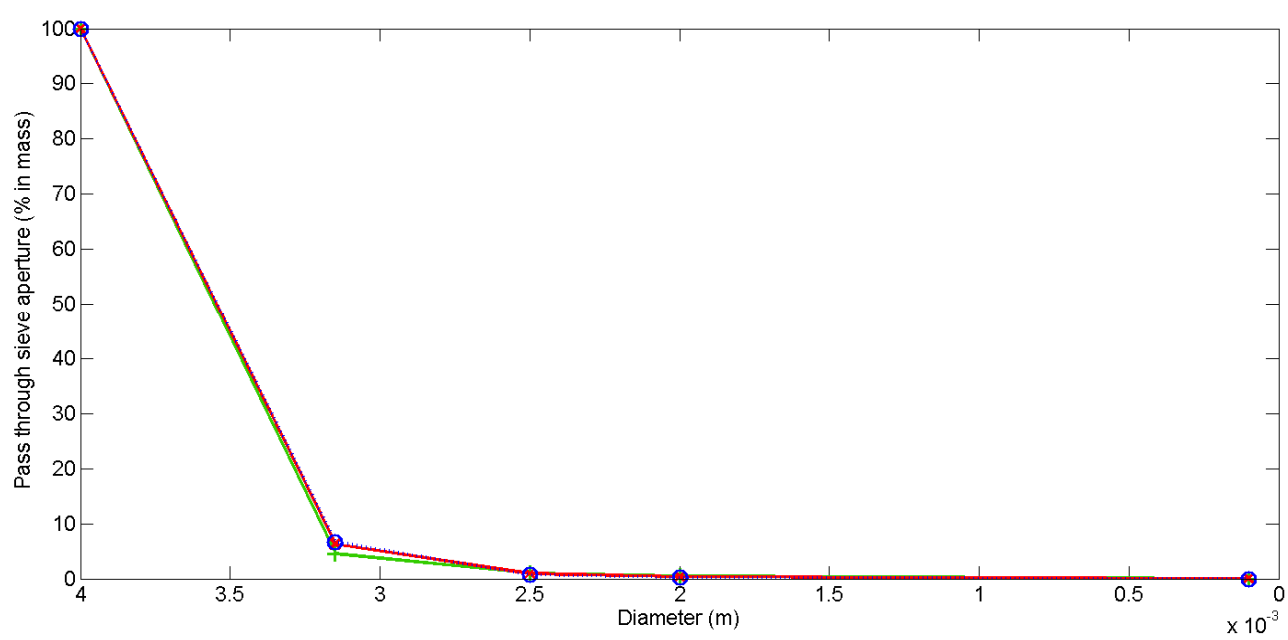

(c)

Fig. 1: Granulometry of the granular materials studied given by 3 tests: (a) soya; (b) colza; (c) rye

The different grains were then characterized using a Hitachi S-3200N scanning electron microscope (SEM), which uses a beam of highly energetic electrons to examine objects on a 
very fine scale, and produces high resolution images of a sample surface. The tests were carried out at ambient temperature under a high vacuum $\left(6.0 \times 10^{-4} \mathrm{~Pa}\right)$ obtained by means of a diffusion pump. For the analysis, the grain samples were laid on $2.5 \times 10^{-2} \mathrm{~m}$ diameter cylindrical container using a double side adhesive copper strip. Then, the container is metalized using gold, under primary vacuum. This step is necessary for non metallic samples to avoid a superficial accumulation of electric charges from the incident electronic beam, emitted by the microscope tungsten filament gun. The resulting images of the grains studied shown in figures 2 (a)-(c) have a characteristic three-dimensional aspect and are useful for judging the surface structure of the sample. Soya and colza seeds have a smooth and regular surface while rye seeds have a rough irregular surface.

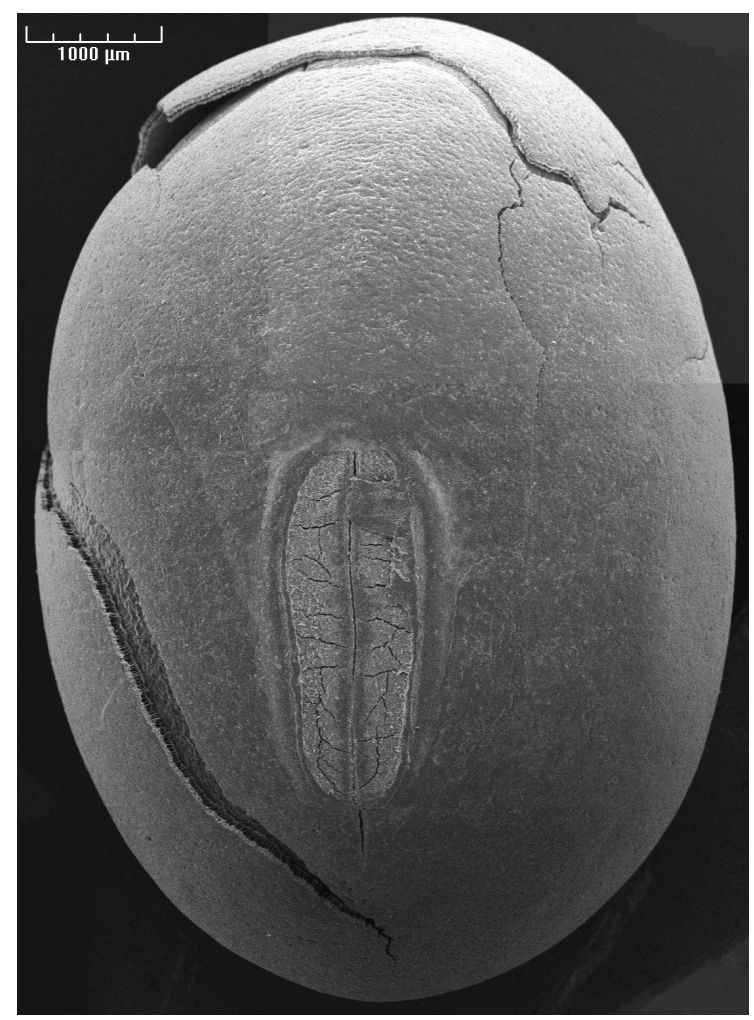

(a)

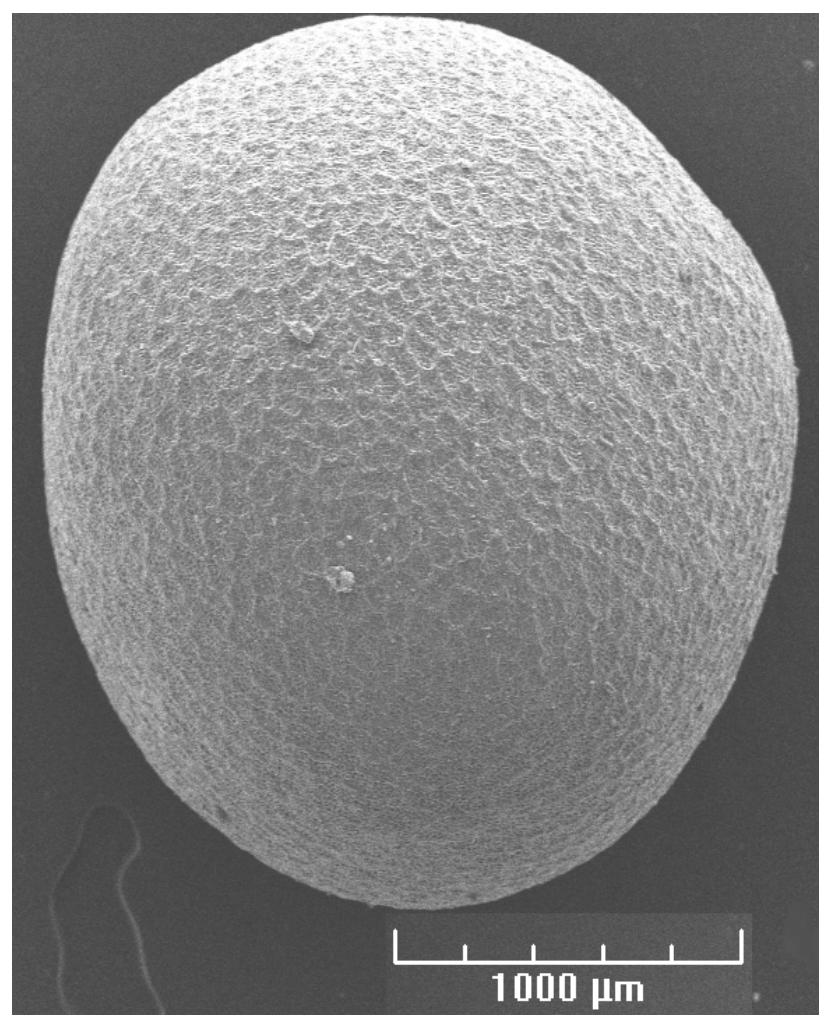

(b)



(c)

Fig.2: SEM images of the tested granular materials: (a) soya; (b) colza; (c) rye 


\section{3 - Flowability}

To determine the flowability of the granular materials, the procedure used is similar to the shear box testing plus a consolidation inside the cell in which a constant normal stress is applied to the sample. The experimental procedure can be summarized as follows: A standard procedure is used to fill the square $6.0 \times 10^{-2} \mathrm{~m}$ side shear cell. Then the bulk solid sample is placed under a given normal stress $\sigma$, obtained by corresponding normal load $N$ on the lid, and subsequently sheared; consequently, the shear force $S$ and the shear stress $\tau$, respectivel, increase over time. By following this procedure, the values measured at failure do not depend on the loading history of the tested sample (Condotta, 2005). In addition, repeatable results can be obtained in this phase because the rupture of a bulk solid sample depends on its consolidation (Lubert, 2000).

Since the shear stress increases to the point of failure, the failure itself is characterized by a stabilization of the shear stress. Table 1 gives the normal stresses applied to all the studied media and the corresponding consolidation stresses. When the consolidation state is reached, a smaller stress $\sigma_{s}$ is applied and the sample is sheared until it breaks at a given shear stress value $\tau_{s}$. The operation is repeated for several normal stresses which are also lower than the consolidation stress.

\begin{tabular}{lcccc}
\hline Consolidation stress $(\mathrm{kPa})$ & 41 & 74 & 128 & 183 \\
\hline Normal stress 1 $(\mathrm{kPa})$ & 19 & 19 & 19 & 19 \\
Normal stress 2 $(\mathrm{kPa})$ & 25 & 33 & 46 & 60 \\
Normal stress 3 $(\mathrm{kPa})$ & 30 & 46 & 74 & 101 \\
Normal stress 4 $(\mathrm{kPa})$ & 36 & 60 & 101 & 142 \\
Normal stress 5 $(\mathrm{kPa})$ & 41 & 74 & 128 & 183 \\
\hline
\end{tabular}

Table 1: The applied normal stresses and the corresponding consolidation stresses

This test was carried out for each of the studied granular materials and graphs similar to figures 3 (a)-(c).

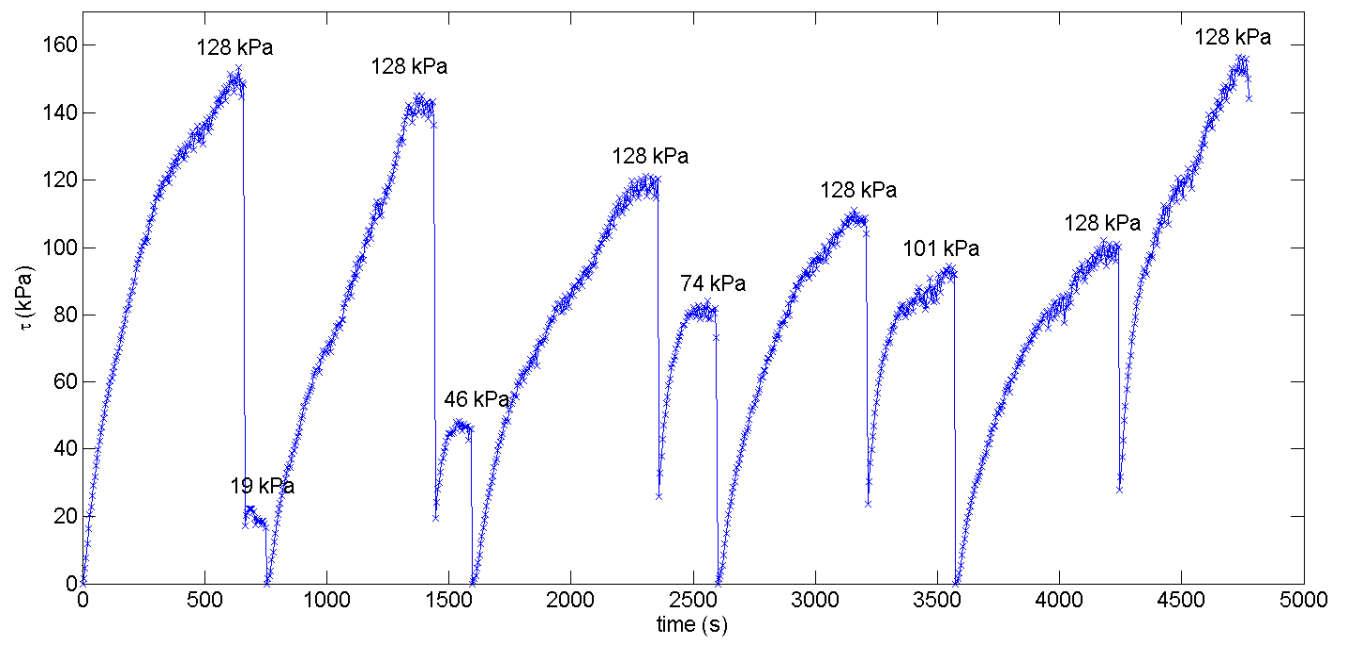

(a) 


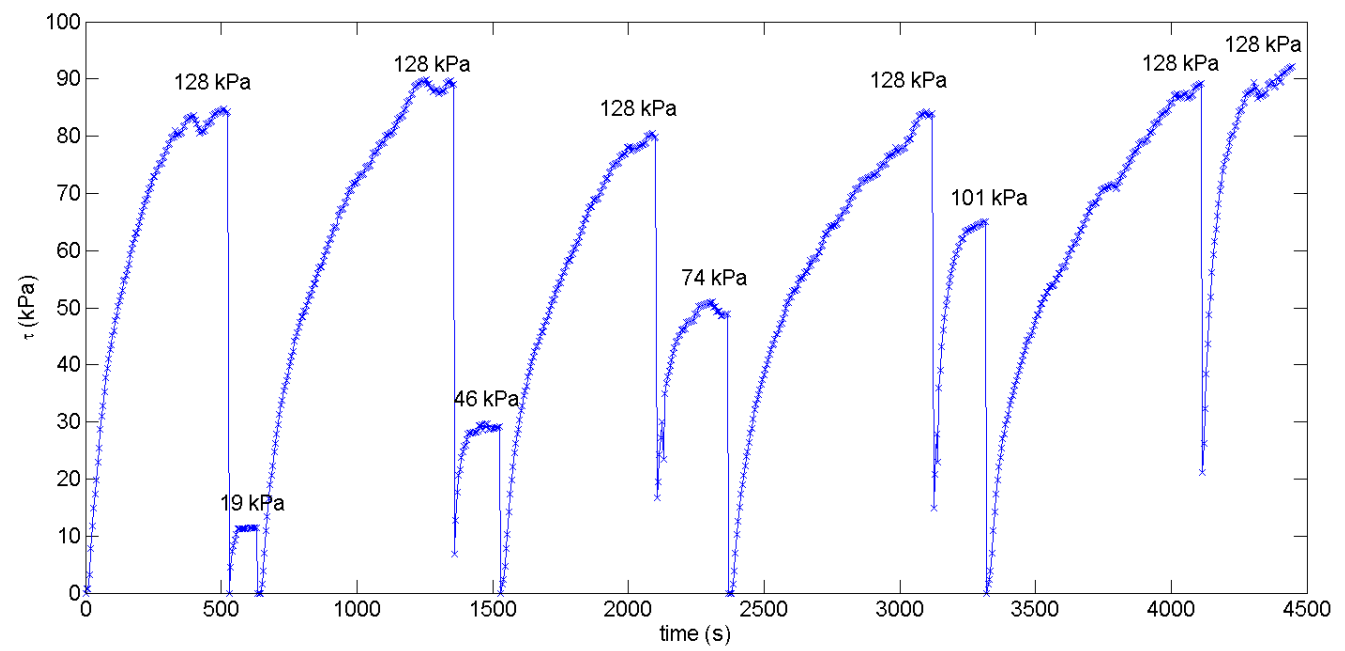

(b)

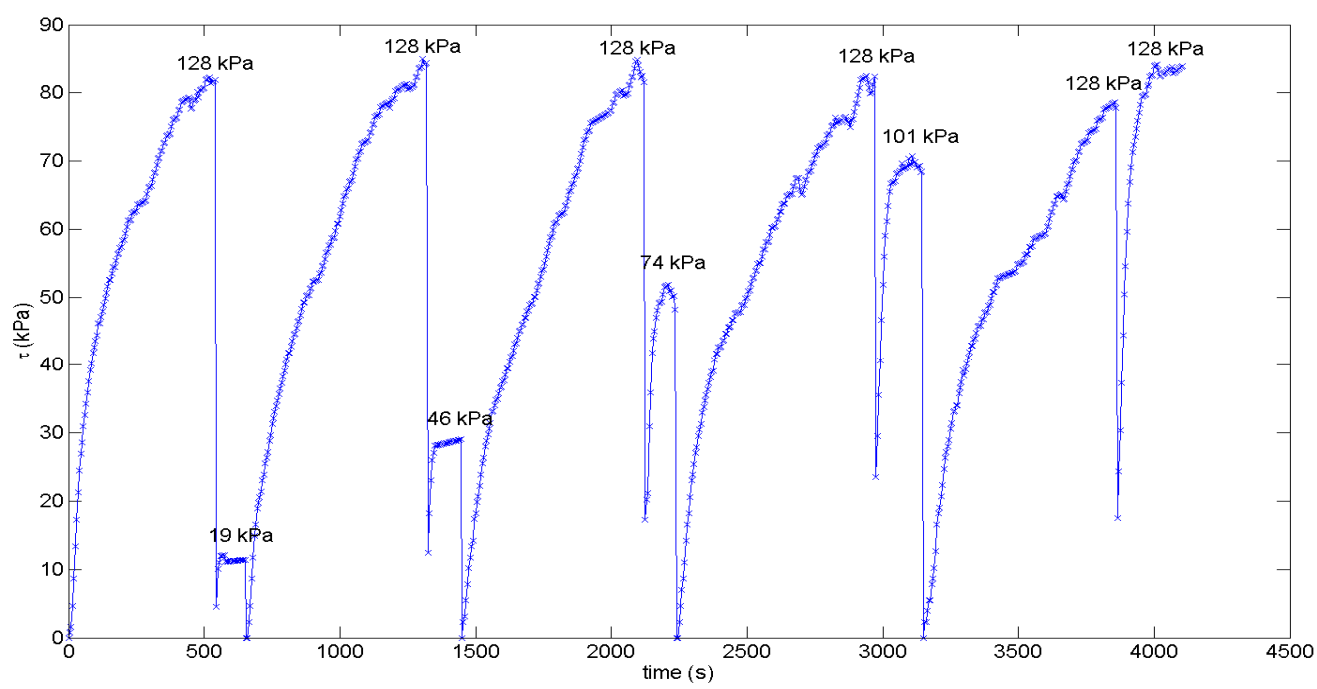

(c)

Fig.3: Typical consolidation tests of the tested granular materials with consolidation stress $\sigma_{\mathrm{c}}=128 \mathrm{kPa}$ : (a) soya; (b) colza; (c) rye

Notice that all the points at failure except the last one $\left(\sigma_{c}, \tau_{c}\right)$ represent the transition from the static state to the dynamic state of the granular material. The yield locus (YL) is a curve passing through all these points at failure $\left(\sigma_{s}, \tau_{s}\right)$. The end point of the YL corresponds to critical flow conditions where initiation of flow is not accompanied by a change in bulk density. Each point on a YL represents that point on a particular Mohr's circle for which failure of the material occurs. A YL is then tangent to all the Mohr's circles representing stress systems under which the material will fail. In addition, for a free-flowing solid (this case), there is only one YL which coincides with a straight line passing through the origin (figures 4 (a)-(c)), tangent to all the Mohr's circles and called Effective Yield Locus (EYL), with equation

$$
\tau=\mu \sigma
$$


In equation (3), $\mu=\tan \delta$ is the coefficient of internal friction, and $\delta$ denotes effective internal friction angle. The cohesion stress $\sigma_{p}$ is the compression stress applied to an arch to break it. The free surface of an arch formed during flow has a tangent plane which is not subject to either normal or tangential stress. The maximal stress supported by a cohesive arch is then given by the main stress of the Mohr's circle passing through the origin and tangent to the EYL. The major consolidation stress $\sigma_{l}$ is the maximal stress which could be applied to the materiel for the considered consolidation state. It is given by the Mohr's circle tangent to the EYL passing through $\left(\sigma_{c}, \tau_{c}\right)$, the limit point of the EYL.



(a)

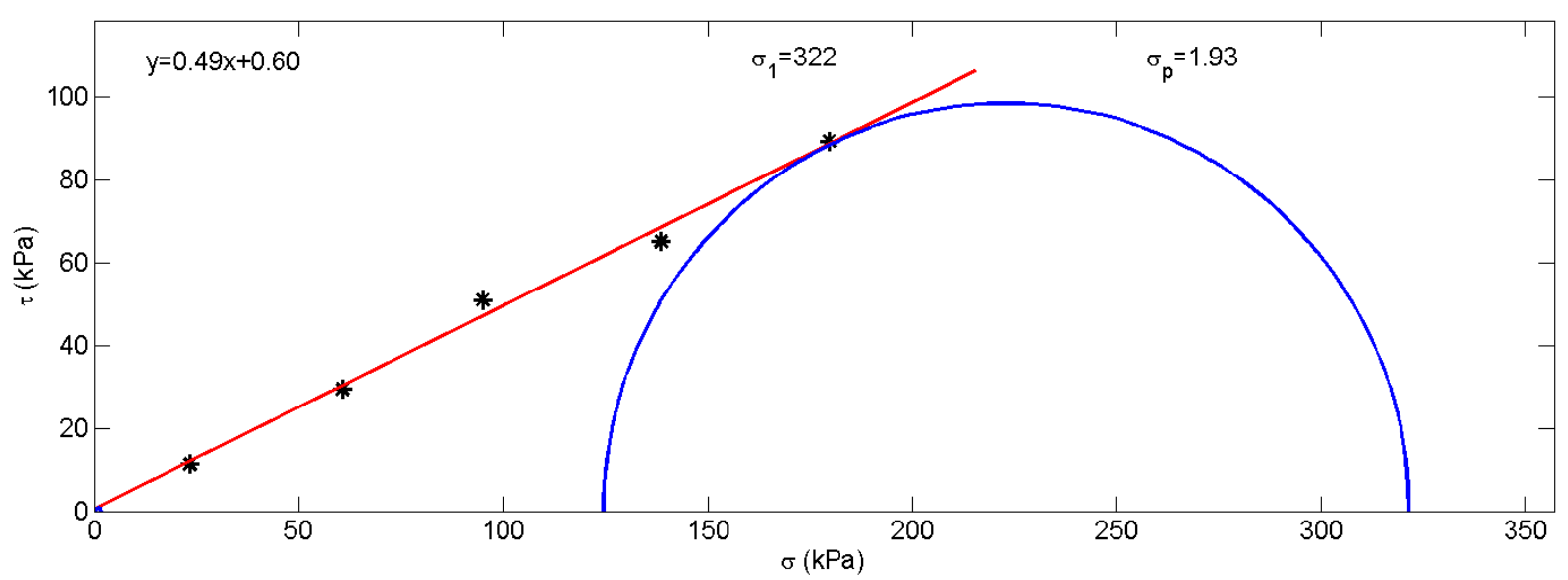

(b) 


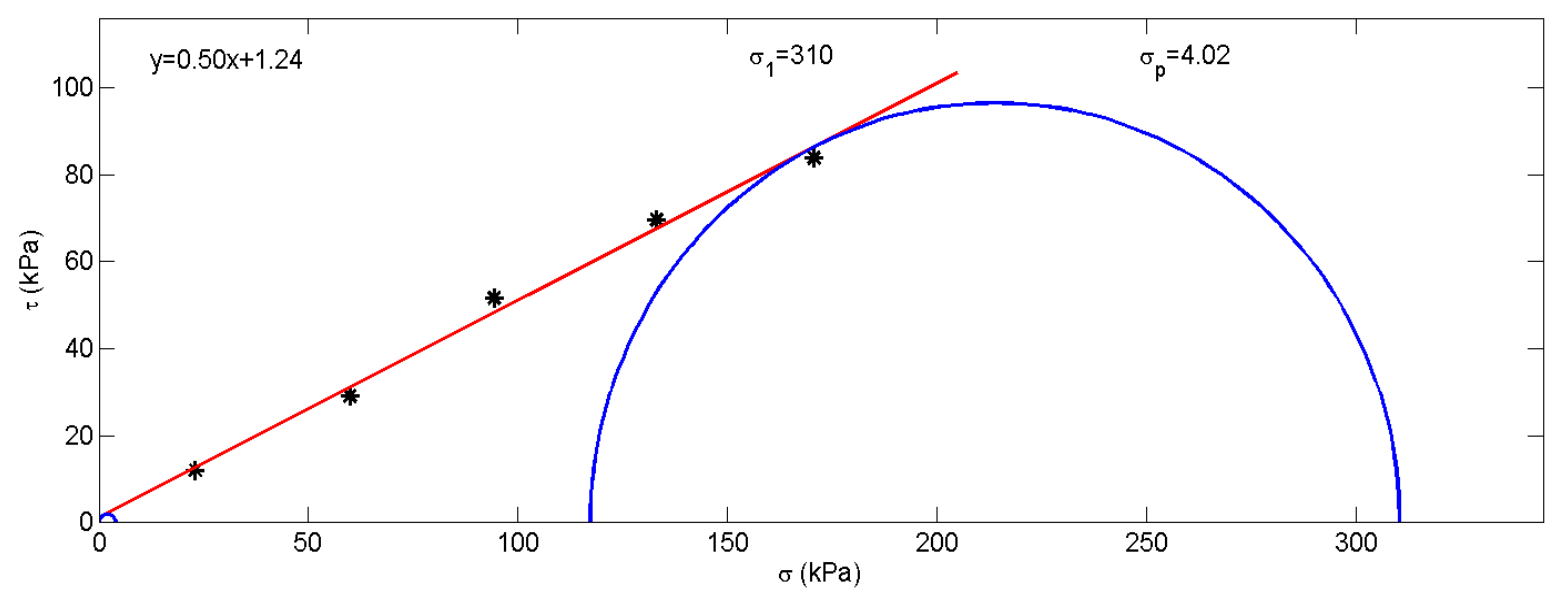

(c)

Fig.4: Typical Effective Yield Locus of the tested granular materials with consolidation stress $\sigma_{\mathrm{c}}=128 \mathrm{kPa}$ : (a) soya; (b): colza; (c) rye

Each EYL produces a couple $\left(\sigma_{l}, \sigma_{p}\right)$. Other tests are then carried out on various consolidations to obtain a flow function. The flow function gives the maximum stress that a free surface (an arch) can bear without collapsing, as a function of the major stress which consolidated the material: $f_{c}=F F\left(\sigma_{l}\right)$. In the $\left(f_{c^{-}} \sigma_{l}\right)$ plane, the closer the obtained points are to the $\sigma_{1}$-axis, the more easily the tested granular material will flow (Schwedes, 2000). The flow functions of the granular materials studied are shown in figure 5. Flowability is then characterized by the ratio $\sigma_{l} / \sigma_{p}$ called the flowability index and the granular materials studied can be classified according to their respective flowability index, i.e. from the highest flowable material to the lowest, soya > colza > rye. This classification agrees with the SEM images shown in section 2, where the colza and soya seeds were observed to have a smooth regular surface and the rye seeds a rough irregular surface. Furthermore, because of the small value obtained for the flowability indexes, it may be assumed that all the tested granular solids undergo a free flow.

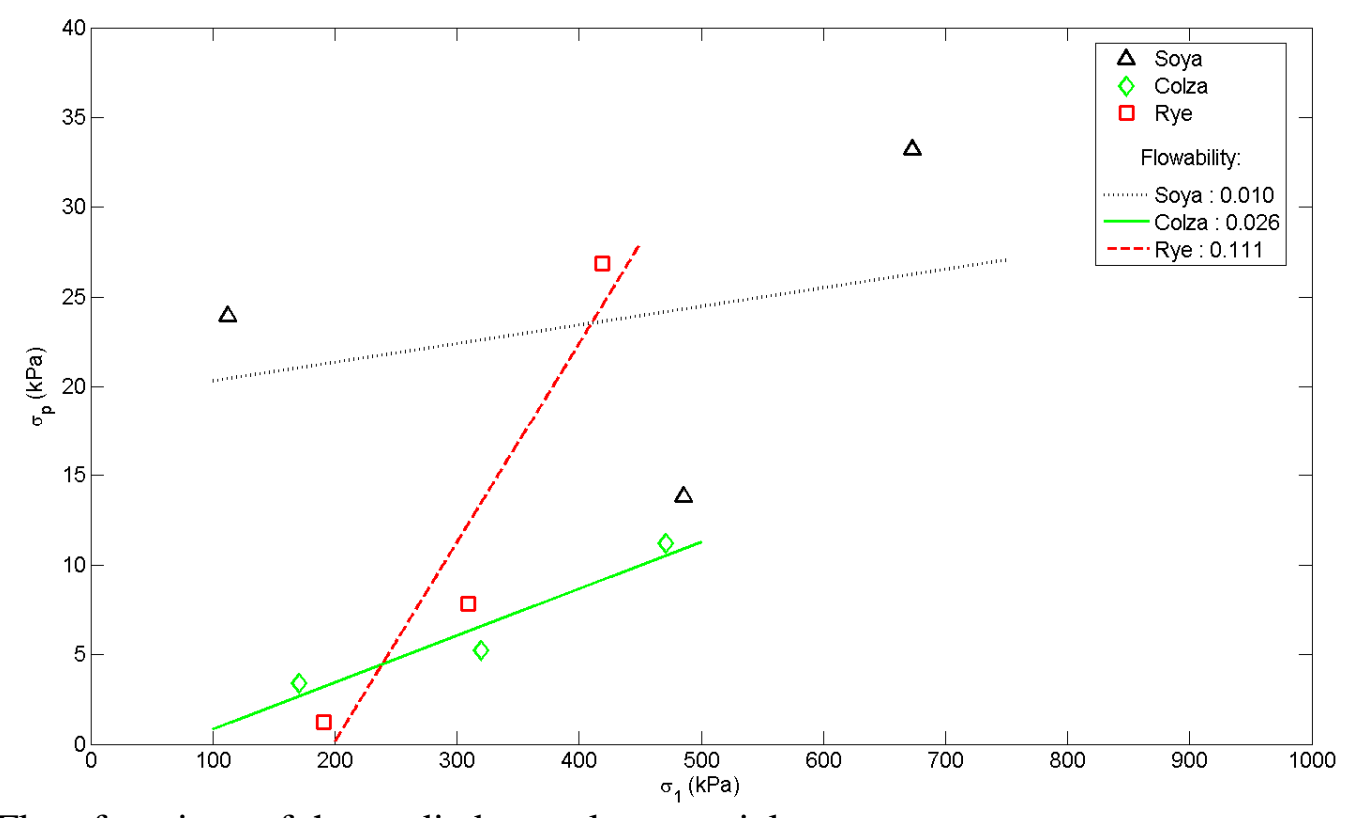

Fig.5: Flow functions of the studied granular materials 


\section{4 - Densities, compacity, porosity and characteristic angles}

For the (dry) granular materials considered, two densities can be defined: the bulk density $\rho_{b}$, which is the mass divided by the occupied bulk volume of the materials, measured here by weighing a $0.5 \mathrm{~L}$ of each type of grain using a test tube and Denver scales of $0.1 \mathrm{~g}$ accuracy, compared to the particle apparent density $\rho_{p}$, which is the total mass of the particle divided by its total volume, the volume including closed pores or gas bubbles within the particle. This density can be measured by liquid or air pyknometry: liquid displacement after a given quantity of water $(0.2 \mathrm{~L}$ in this case) is poured into a given quantity of grains $(200 \mathrm{~g}$ here). The bulk density $\rho_{b}$ is the mass divided by the bulk volume occupied by the materials, while the apparent density is the net weight of the dry materials divided by the net volume of the materials calculated by subtracting the volume of the added liquid from the bottle's volume.

When a sample of granular material falls freely from a feeder, it forms a cone. The angle $\theta$ of this cone increases during the flow up to a given maximum called the start angle $\theta_{\text {start }}$, where an avalanche occurs, characterized by a surface flow of the medium and, therefore, the cone angle decreases down to a given minimum called the stop angle $\theta_{\text {stop }}$. The critical angles $\theta_{\text {start }}$ and $\theta_{\text {stop }}$ are characteristic for a given granular medium.

Material porosity is the volume of the voids within the medium (i.e. the volume occupied by air) divided by the total, overall volume of the medium. For a unit volume of the bulk granular material, the following mass balance holds:

$$
\rho_{b}=\rho_{p}(1-\Phi)+\rho_{a i r} \Phi
$$

As the air density $\rho_{\text {air }}$ is low relative to the grain density and may be ignored. and The porosity $\Phi$ can thus be calculated as:

$$
\Phi=1-\frac{\rho_{b}}{\rho_{p}}
$$

The EYL obtained in the previous section for each tested granular material is a straight line tangent to the corresponding Mohr's circles and passing through the origin of the $(\sigma, \tau)$ plane. Its slope, defined as the effective internal friction angle $\delta$ characterizes the friction caused by solid particles flowing against each other and thus directly influences the flow properties of the materials. It is used in Jenike's method (1964) of silo design. Table 2 shows the values obtained in this work for the different characteristics of each granular material

\begin{tabular}{|c|c|c|c|}
\hline Materials & Soya & Colza & Rye \\
\hline Bulk density $\left(\mathrm{kg} / \mathrm{m}^{3}\right)$ & $1177 \pm 18$ & $1053 \pm 14$ & $1212 \pm 19$ \\
\hline Apparent density $\left(\mathrm{kg} / \mathrm{m}^{3}\right)$ & $682 \pm 4$ & $641 \pm 4$ & $741 \pm 4$ \\
\hline Porosity & $0.42 \pm 0.01$ & $0.39 \pm 0.01$ & $0.39 \pm 0.01$ \\
\hline $\begin{array}{l}\text { Effective internal friction } \\
\text { angle }\left(^{\circ}\right)\end{array}$ & 28.8 & 28.3 & 25.2 \\
\hline Stop angle $\left(^{\circ}\right)$ & 30.3 & 32.0 & 29.2 \\
\hline Start angle $\left({ }^{\circ}\right)$ & 34.2 & 35.6 & 33.6 \\
\hline
\end{tabular}
studied.

Table 2: Characteristics of the granular materials tested 


\section{5 - Conclusion}

The prediction of the behavior of a granular solid is useful to the engineer. This paper concerns the flowability properties of dry granular materials. The specific bulk characteristics and properties, called flow properties, of soya, colza and rye seeds that affect flow were considered.

Numerous physical properties are defined in the literature, and only the most relevant were characterized, namely shape, size, critical angles and particle densities. These flow properties refer to the behavior of the bulk material and arise from the collective forces acting on individual particles. The grain sizes were determined using appropriate sieves. The respective average diameters were fairly large, the matters were dry and the absence of very fine particles and humidity were noted, so the Van der Waals, electrostatic and surface tension forces were ignored in this study.

Observation of SEM images shows that the soya and colza seeds have a smooth regular surface with an oval shape while the rye seeds have a rough irregular surface with an elongated shape. Thus, the effect of shape and surface on the flowability is more favourable for the soya and colza seeds than for the rye seeds. The different critical angles were measured and found to be less than $36^{\circ}$ and thus it can be assumed that all three matters tested are free-flowing. In addition, their respective porosities are (about 40\%) those which characterize free-flowing materials. Conversely, the densities of dry granular solids cannot be directly used to characterize their flowability. Nevertheless, measure of bulk density gives an estimate of how much volume the matter will occupy in the silo, the weight being the main cause of consolidation and failure, necessary for its flow. Bulk and apparent densities of the different matters were then measured using accurate equipment.

The mechanical characterization of the grains was then carried out, using a modified shear box testing with a procedure similar to Jenike's test. The effective internal friction angle of each tested granular material was derived from the corresponding EYL. For a given material, a flow function which is the aptitude of the material to undergo consolidation under stress is then derived from different EYL obtained with various consolidations. The flow function obtained with this test is an intrinsic flow characteristic of the granular material studied and is used for the silo design. A material which undergoes a higher consolidation (steeper flow function) will tend to form steadier arches and will require a higher hopper slope and a larger outlet diameter. The following classification of the tested materials according to their respective flowability index, i.e. from the highest flowable material to the lowest was then obtained: soya > colza > rye. The flow function obtained with this test is an intrinsic flow characteristic of the studied granular material and is used for the silo design.

\section{Acknowledgements}

This work was funded by a PRIR contract involving the Port de commerce de Brest (Brest Commercial Port), La Région Bretagne (Brittany Region Council) and the Université de Bretagne Occidentale.

\section{References}

Carr, R.L. (1965a). Classifying flow properties of bulk solids, Chem. Eng., 72(3), 69-72

Carr, R.L. (1965b). Particle behaviour, storage and flow, British Chemical Engineering Chemistry, 15(12), 1541-1549

Carr, R.L. (1965c). Evaluating Flow Properties of Solids, Chem. Eng. 18(1), 163-168 
Condotta, R. (2005). "Coulabilité des poudres cohésives : mesures aux faibles contraintes, granulaires humides et application à une poudre", Thèse Institut National Polytechnique de Toulouse - France (French)

Costet, J. and Sanglerat, J. (1975). "Cours de Mécanique des sols », $2^{\text {ème }}$ édition, tome 1, Dunod, Paris (French)

GDR Midi (2004). On dense granular flows. Eur. Phys. J. E, 14, 341-365.

Haaker, G. and Rademacher, F.J.C. (1983). Direckte Messung der Fließeigenschaften von Schüttgütern durch Messung mit einem abgeänderten Triaxialgerät, Aufbereitungs-Technik, 11, 647-655

Jenike, A.W. (1964). Storage and flow of solids. Bull. $\mathbf{n}^{\circ}$ 123, Eng. Exp. Station, Univ. Utah, Salt Lake City

Lancelot, L. and Shahrour, I. (1994). Mechanical behaviour of a chemical powder at low stress levels, Influence of temperature and humidity, Powder Handling \& Processing, 6(3), 303-308

Lubert, M. (2000). “Aptitude à l'écoulement d'un milieu granulaire : exploitation des instabilités de cisaillement et évaluation du vieillissement", Thèse Ecole des Mines D'AlbiCarmaux - France (French)

Nowak, M. and Schwedes, J. (1992). An investigation on the pure shearing of cohesive limestone with the true biaxial shear tester, Chem. Eng. Technol., 15(5), 295-299

Peleg, M; (1977). Flowability of food powders and methods for its evaluation, J. Food Process, 1, 303-328

Prescott, J.K. and Barnum, R.A. (2000). On powder flowability, Pharmaceutical Technol., 10, 60-84

Schulze, D. (1996a). Measuring Powder Flowability: A Comparison of Test Methods, Part I", Powder Bulk Eng., 10(4), 45-61

Schulze, D. (1996b). Measuring Powder Flowability: A Comparison of Test Methods, Part II”, Powder Bulk Eng., 10(6), 17-28

Schwedes, J. (2000). Testters for measuring flow properties of particulate solids. Powder Handling and Processing, 12(4), 337-354.

Svarovski, L. (1987). "Power testing guide: Methods of measuring the physical properties of bulk powders", Elsevier, London

Teunou, E. (1997). "Caractérisation de l'écoulement instantané et après un temps de stockage de poudres alimentaires. Evaluation de diverses méthodes et appareils, dont une nouvelle cellule annulaire ", Thèse ENSIA, Massy - France ( French)

Williams, J.C.; Birks, A.H. and Bhattacharya, D. (1971). The direct measurement of the failure function of a cohesive powder, Powder Technol., 4, 328-337 